\title{
An Exploration of Life Satisfaction, Psychological Distress and Psychological Well-being among College Students
}

\author{
Rehana Abdullah $^{1}$, Saima Mushtaq ${ }^{2}$
}

\section{ABSTRACT}

The present study was carried out to explore life satisfaction, psychological distress and psychological wellbeing in a sample group of 100 college students. The sampling technique involved was purposive and the tool adopted to measure the mentioned constructs was Mental health inventory (MHI-38) developed by Davies AR, Sherbourne CD, Peterson JR and Ware JE (1998). The data collected was carefully scrutinized and condensed into excel sheet so that all information could be bought into proximity. In order to achieve the objective of the present study, the tabulated data was analyzed by using Pearson's product movement correlation and ttest with the help of SPSS. The main finding of the study was that life satisfaction has significant negative correlation with psychological distress but positive correlation with psychological wellbeing, while as psychological distress and psychological wellbeing were found to have negative correlation with each other.

Keywords: Life Satisfaction, Psychological Distress and Psychological Wellbeing

A plethora of studies have been conducted towards the assessment of mental health, which in essence refers to the development and application of a set of practical principles directed towards the achievement and maintenance to the psychological wellbeing of human organisms and prevention of mental disorder and maladjustment (Bernad, 1951 and Jhorpe, 1950).There are many psychological constructs like life satisfaction, psychological distress and psychological wellbeing which serve as indicators regarding the mental health of a person. Life Satisfaction is the central aspect of human welfare. It is ultimate goal and every human being strives to achieve this goal throughout the life. It is a multidimensional concept related to psychological and environmental life conditions. (Wolman, 1973) defined life satisfaction as attainment of a desired end and fulfillment of essential conditions. Satisfaction in life does not lie in the length of days, but in the use we make of them. A man may live long yet may get little from life. Thus satisfaction in life does not depend on number of years, but on will (Bartlett, 1977). In judging about the satisfaction of lives individuals set a standard which they perceive appropriate for circumstances of lives (Diener et.al 1985). It may be possible that a person is satisfied with

\footnotetext{
${ }^{1}$ Contractual Lecturer, G.D.C Anantnag, J\&K

${ }^{2}$ University of Kashmir, J\&K

*Corresponding Author

(C) 2015 I R Abdullah, S Mushtaq; licensee IJIP. This is an Open Access Research distributed under the terms of the Creative Commons Attribution License (http://creativecommons.org/licenses/by/2.0), which permits unrestricted use, distribution, and reproduction in any Medium, provided the original work is properly cited.
} 


\section{An Exploration of Life Satisfaction, Psychological Distress and Psychological Well-being among College Students}

almost all domains (e.g. health, wealth marriage education etc) of life but may not be still dissatisfied with particular domain which may negatively affect his/ her overall judgment about life satisfaction. As far as psychological distress is concerned, it is a general term that is used to describe unpleasant feelings or emotions that impact the level of functioning. In other words it is psychological discomfort that interferes with daily living activities. It can result in negative views of environment, others and the self. Sadness, anxiety, distraction and symptoms of mental illness are manifestations of psychological distress. Since no two people experience one event the exact same way, psychological distresses is a subjective experience. That is, the severity of psychological distress is dependent upon the situation and how we perceive it. Psychologically distressed individual can also experience problems in the way they think, feel or behave. In other words their thinking, feeling and behavior is all mixed up. This significantly interferes with their relationships with other people, their work and enjoyment of life. As far as psychological wellbeing is concerned, it is the combination of feeling good and functioning effectively. Sustainable wellbeing does not require individuals to feel good all the time, the experience of painful emotions e.g. disappointment, failure, grief is a normal part of life and being able to manage these negative or painful emotions essential for long term wellbeing. It is however compromised when negative emotions are extreme or very long lasting and interfere with a person's ability to function in his or her daily life. It refers to how people evaluate their lives. According to Diener (1997) these evaluations may be in the form of cognitive or in the form of effect. The cognitive part is information based appraisal of one's life that is when a person gives conscious evaluative judgments about ones satisfaction with life as a whole. The effective part is a hedonic evaluation guided by emotions and feelings such as frequency with which people experience pleasant/unpleasant mood in reaction to their life. Psychological wellbeing can be defined as a dynamic state, in which an individual is able to develop their potential, work productively and creatively, build strong and positive relationship with others and contribute to their communities. Opree(2012) ; Ray A, Halder S, Goswami N (2012); Winefield H R, Gill T.K, Taylor W A (2012); Vazquez F.L (2012) ; Afifi T.O, Natalia P.M (2012) ; Mehmet (2013) and Zhang J (2013) are some of the important authors who have conducted in depth studies pertaining to the understudy constructs.

\section{Purpose of Study}

A lot of research has been conducted regarding life satisfaction, psychological distress and psychological wellbeing. Studies conducted so far have shown that these constructs are correlates of each other and give a picture of the mental health of a person (Ware et.al, 1984; Lanier et.al, 2001; Kelly, 2004; Lisa, 2006; Saharian, 2010). In J\&K state there is dearth of studies which have studied these constructs together on the sample group of college students. In this context, the present study aims to assess the life satisfaction, psychological distress and psychological wellbeing among the college students. It is hoped that this study may contribute to the literature on the said variables. Further this study will help the researchers for better 
understanding of the relationship between these variables that in turn may be beneficial for all the planning bodies concerned with improvement of mental health among students.

\section{OBJECTIVES}

1. To assess the life satisfaction, psychological distress and psychological wellbeing among college students.

2. To study correlation between life satisfaction and psychological distress of college students.

3. To study correlation between life satisfaction and psychological wellbeing of college students.

4. To study correlation between psychological wellbeing and psychological distress of college students.

\section{Hypotheses}

On the basis of objectives framed above, the following null hypotheses have been formulated:

1. $\mathrm{H}_{01}$ : There is no significant correlation between life satisfaction and psychological distress of college students.

2. $\mathrm{H}_{02}$ : There is no significant correlation between life satisfaction and psychological wellbeing of college students.

3. $\mathrm{H}_{03}$ : There is no significant correlation between psychological wellbeing and psychological distress of college students.

\section{Sample description}

The sample of the present study consisted of 50 male and 50 female college students between the age range of 18-20 years belonging to urban area and the purposive sampling technique was used in this regard.

\section{Tools used}

The constructs were measured by the subscales of Mental health inventory (MHI-38) developed by Davies AR, Sherburne CD, Peterson JR and Ware JE (1998).

\section{Analysis of data}

The data collected by the questionnaire was carefully scrutinized and condensed into excel sheet so that all information could be bought into proximity. After that relevant statistical techniques were used with the help of SPSS. 


\section{RESULTS \& INTERPRETATION}

Table 1: Descriptive Statistics of sample group.

\begin{tabular}{|l|c|c|l|c|}
\hline Construct & N & Range & Mean & Std. Deviation \\
\hline life satisfaction & 100 & $1-5$ & 3.53 & 0.96 \\
\hline $\begin{array}{l}\text { Psychological } \\
\text { distress }\end{array}$ & 100 & $38-140$ & 73.23 & 17.06 \\
\hline $\begin{array}{l}\text { Psychological } \\
\text { wellbeing }\end{array}$ & 100 & $18-78$ & 52.32 & 10.94 \\
\hline
\end{tabular}

As per the earlier table, the mean of the sample group on life satisfaction is 3.53 and standard deviation is 0.96 ; the mean of sample on psychological distress is 73.23 and standard deviation is 17.06; and the mean of sample group on psychological wellbeing is 52.32 and standard deviation 10.94 .

Table 2: Showing frequency distribution of sample group on life satisfaction, psychological distress and psychological wellbeing.

\begin{tabular}{|l|l|l|l|l|l|l|}
\hline \multirow{2}{*}{ construct } & \multicolumn{2}{|c|}{ Low } & \multicolumn{2}{c|}{ Average } & \multicolumn{2}{c|}{ High } \\
\cline { 2 - 8 } & f & \%age & f & \%age & f & \%age \\
\hline Life satisfaction & 5 & $5 \%$ & 95 & $95 \%$ & 0 & $0 \%$ \\
\hline Psychological distress & 11 & $11 \%$ & 88 & $88 \%$ & 1 & $1 \%$ \\
\hline Psychological wellbeing & 1 & $1 \%$ & 90 & $90 \%$ & 9 & $9 \%$ \\
\hline
\end{tabular}

It is evident from the above table that $5 \%$ of the college students score low on life satisfaction, 95\% score average where as none of students have scored high; In case of psychological distress, $11 \%$ score low, $88 \%$ score average where as only $1 \%$ score high; and lastly in case of psychological wellbeing $1 \%$ score low; $90 \%$ score average and 9\% score high.

Table 3: Showing the correlation between life satisfaction and psychological distress:

\begin{tabular}{|c|c|}
\hline Constructs & Pearson's Correlation \\
\hline Life satisfaction & $-0.26($ significant at 0.05 level) \\
\hline
\end{tabular}

As per the above table the relationship of life satisfaction and psychological distress is significant at 0.05 level. Hence our null hypothesis $\mathrm{H}_{01}$ i.e. There is no significant correlation between life satisfaction and psychological distress of college students stands rejected. 
An Exploration of Life Satisfaction, Psychological Distress and Psychological Well-being among College Students

Table 4: Showing correlation between life satisfaction and psychological wellbeing:

\begin{tabular}{|l|c|}
\hline \multicolumn{1}{|c|}{ Constructs } & Correlation \\
\hline $\begin{array}{l}\text { Life satisfaction } \\
\text { Psychological wellbeing }\end{array}$ & 0.34 ( significant at 0.05 level) \\
\hline
\end{tabular}

As per the above table the relationship of life satisfaction and psychological wellbeing is significant at 0.05 level. Hence our null hypothesis $\mathrm{H}_{02}$ i i.e. there is no significant correlation between life satisfaction and psychological wellbeing of college students stands rejected.

Table 5: Showing correlation between psychological distress and psychological wellbeing:

\begin{tabular}{|l|l|}
\hline constructs & Correlation \\
\hline Psychological distress & $-0.425^{*}$ ( significant at 0.05 level) \\
Psychological wellbeing & \\
\hline
\end{tabular}

As per the above table the relationship of psychological distress and psychological wellbeing is significant at 0.05 level. Hence our null hypothesis $\mathrm{H}_{03}$ i.e. There is no significant correlation between psychological distress and psychological wellbeing of college students stands rejected.

\section{CONCLUSION}

The present study was conducted to examine the life satisfaction, psychological distress and psychological wellbeing among college students comprising of equal number of boys and girls. The main findings of the study are:

- It was found that $5 \%$ of the college students showed low levels of life satisfaction and $95 \%$ showed average levels of life satisfaction. In case of psychological distress $11 \%$ of the college students showed low , 88\% showed average and only $1 \%$ of the sample group showed high levels of the same. Likewise on psychological wellbeing just $1 \%$ of the sample group scored low, 90\% scored average and 9\% scored high.

- Life satisfaction showed significant negative correlation with psychological distress and significant positive correlation with psychological wellbeing

- Psychological distress and psychological wellbeing were found to have significant negative correlation with each other.

These findings are in consonance with the research conducted by Lisa et.al (2006) ;Winefield et.al (2012); Mehmet et.al (2013); Zhang et.al (2013) and Jarman et.al (2014).It is highly recommended that intervention programs should be devised to train students from time to time so as to increase their psychological wellbeing and life satisfaction and decrease their psychological distress levels. 


\section{REFERENCES}

Afifi T.O, Natalia P.M (2012) Physical punishment and mental disorders, Journal of American academy of pediatrics 130(2):1-9.

Kelly and William E (2004) Sleep length and life satisfaction in college students; College student journal, 38(3):428-430.

Lanier C.A, Nicholson T, Duncan D (2001) studied on drug use and mental wellbeing among undergraduate and graduate students, journal of drug education 31(3):239-248.

Lisa P, Alejandro D, William E (2006) An examination of worry and life satisfaction among college students, the journal of academy, 4(5):331.

Mehmet (2013) studied on psychological wellbeing and internet addiction among university students, Journal of educational technology 12(3).

Opree S J, Buijzen M, Valkenburg P M (2012) Lower life satisfaction related to materialism in children frequently exposed to advertising; the American academic pediatrics, 130(3): 486-491.

Ray A, Halder S, Goswami N (2012) Academic career development stress and mental health of higher secondary students; international journal of educational psychology, 1(3):257277.

Sahraian A (2010) Sleep disruption and its correlation to psychological distress among medical students, Journal of shiraz-e-medical 11(1).

Vazquez F.L (2012) Study on psychological distress and related factors in female college students. Journal of American college health 60(3):219-225.

Winefield H R, Gill T.K, Taylor W A (2012) Studied on exploration of self report measure for psychological wellbeing; 2:3.

Zhang J (2013) life satisfaction and its correlates among college students, Journal of psychiatry. 